\title{
SCIENTIFIC REPORTS

\section{OPEN Female reproductive factors and risk of external causes of death among women: The Japan Public Health Center-based Prospective Study (JPHC Study)}

Received: 21 January 2019

Accepted: 16 September 2019 Published online: 04 October 2019

\begin{abstract}
Shiori Tanaka ${ }^{1,2}$, Sarah K. Abe ${ }^{1}$, Norie Sawada $\mathbb{1}^{1}{ }^{1}$, TaikiYamaji ${ }^{1}$, Taichi Shimazu ${ }^{1}{ }^{1}$, Atsushi Goto ${ }^{1}$, Motoki Iwasaki ${ }^{1}$, Hiroyasu 1 Iso $^{3}$, Tetsuya Mizove ${ }^{4}$, Manami Inove $\mathbb{D}^{1}$ \& Shoichiro Tsugane $\mathbb{B}^{1}$
\end{abstract}

Although empirical data suggest a possible link between female reproductive events and risk of nonfatal accidents and suicidal behaviors, evidence to determine these effects on mortality is scarce. This study investigated the association between female reproductive factors and the risk of external causes of death among middle-aged Japanese women. We used a population-based cohort study consisting of 71698 women residing in 11 public health center areas across Japan between 1990 and 1994. Multivariable-adjusted Cox proportional hazard regression models were used to estimate hazard ratios (HRs) of the risk of all external causes, suicide, and accidents according to female reproductive factors at the baseline survey. During 1028583 person-years of follow-up for 49279 eligible subjects (average 20.9 years), we identified 328 deaths by all injuries. Among parous women, ever versus never breastfeeding [0.67 (95\% Cl: 0.49-0.92)] was associated with a decreased risk of all injuries. Risk of suicide was inversely associated with ever versus never parity [0.53 ( $95 \% \mathrm{Cl}: 0.32-0.88)]$. A lower risk of death by accidents was seen in ever breastfeeding [0.63 (95\% Cl: 0.40-0.97)] compared to never breastfeeding. This study suggests that parity and breastfeeding are associated with reduced risk of death by all external causes, suicide and/or accidents among Japanese women.

Globally, more than five million people die each year as a result of external causes. These deaths have now become a major public health concern ${ }^{1}$. Japan has experienced a slightly decreasing suicide rate since its peak in $1998^{2}$. However, more than 20000 people die annually by suicide, giving Japanese women the second highest suicide rate among OECD countries after Korea ${ }^{3}$.

Early epidemiological studies focused on potential associations between reproductive factors, and suicide behaviors and nonfatal accidents. In contrast, few studies examined external causes of death. The first report on a possible link between parity and suicide was Durkheim's hypothesis in 1966, which suggested that parenthood rather than marriage per se was an important factor in protecting against suicide ${ }^{4}$. Reported or proposed protective factors for suicide include being pregnant ${ }^{5,6}$, having children ${ }^{4,7}$, ever or multi parity ${ }^{8-12}$, late age at first birth $^{8}$, and never use of oral contraceptives (OCs) ${ }^{13}$. Similar results were also noted for deaths by accident ${ }^{11,13-16}$. However, these findings remain inconsistent, and a specific mechanism to explain these associations has not been provided, except with regard to parity $12,13,17,18$.

${ }^{1}$ Epidemiology and Prevention Group, Center for Public Health Sciences, National Cancer Center, 5-1-1 Tsukiji, Chuo-ku, Tokyo, 104-0045, Japan. ${ }^{2}$ Department of Global Health Policy, Graduate School of Medicine, The University of Tokyo, 7-3-1 Hongo, Bunkyo-ku, Tokyo, 113-0033, Japan. ${ }^{3}$ Public Health, Department of Social Medicine, Osaka University Graduate School of Medicine, 2-2 Yamadaoka, Suita, Osaka, 565-0871, Japan. ${ }^{4}$ Department of Epidemiology and Prevention, Center for Clinical Sciences, National Centre for Global Health and Medicine, 1-21-1 Toyama, Shinjuku-ku, Tokyo, 162-8655, Japan. Correspondence and requests for materials should be addressed to M.I. (email: mnminove@ncc.go.jp) 


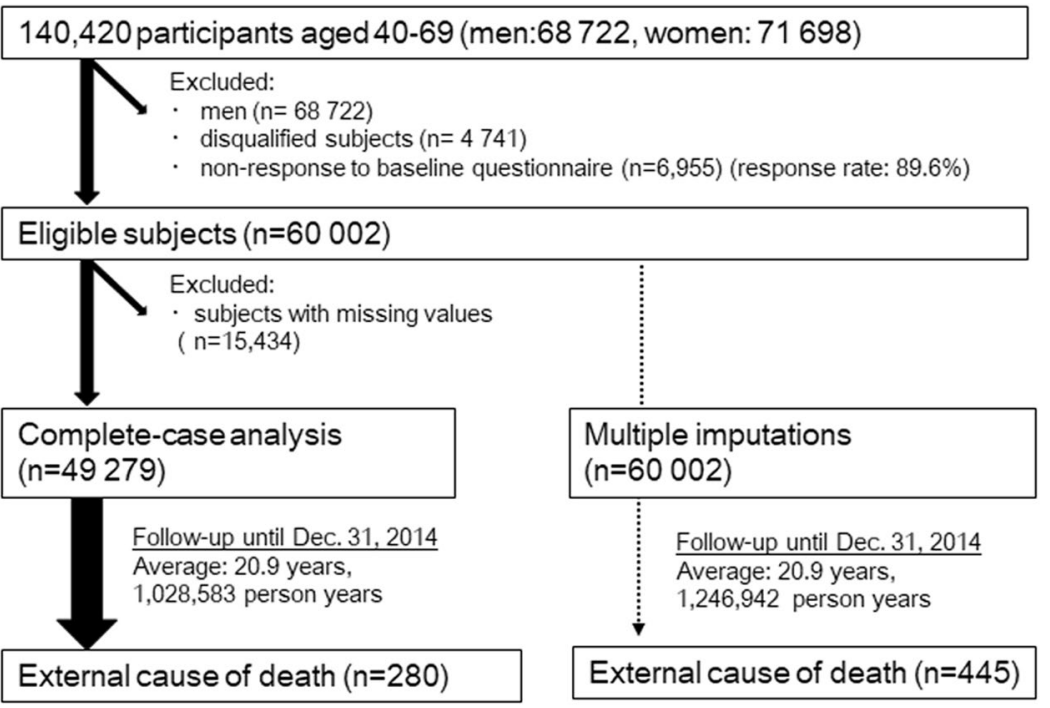

Figure 1. Study flow.

Suicide attempts and completion are significantly more frequent at times of low or rapid states of decline in endogenous sex steroids (estrogen and progesterone), such as peri-menopause ${ }^{19}$, the postpartum period ${ }^{20}$, and the premenstrual and menstrual phases of the cycle ${ }^{21,22}$. The complicated interplay among female sex steroids and the neuroregulatory system may link reproductive events to mental illness and suicidality ${ }^{20,22,23}$. Since female suicide completers are more likely to have a history of self-harm/suicide attempts ${ }^{24}$, even events that occurred long before, such as menarche, may be worth considering as risk factors of their lifetime suicidality. Women with a hypoestrogenic period such as menopause may be at increased likelihood of accidents due to a decrease in musculoskeletal $^{25}$ and cognitive function ${ }^{26,27}$.

To date, no study has comprehensively investigated reproductive factors as potential markers for mortality risk of external causes. Here, we investigated the association between female reproductive factors and risk of all-cause and major causes of external deaths among middle-aged Japanese women.

\section{Methods and Materials}

Study population. We used data of the Japan Public Health Center-based Prospective Study (JPHC Study), which is an ongoing population-based prospective cohort study. A total of 140420 participants (68 722 men and 71698 women) aged 40-69 in 11 public health center (PHC) areas nationwide enrolled between 1990 and 1994 (Fig. 1). The study areas were selected from across Japan based on geographical, environmental and cultural differences, and details of the JPHC Study have been described elsewhere ${ }^{28-30}$. A self-administered questionnaire was conducted at entry and at 5- and 10-year additional surveys to collect comprehensive information including lifestyle, personal and family medical history, diet and reproductive events. All methods described in the current study has been approved by the Institutional Review Board of the National Cancer Center (approval number: 2001-021) with reference to relevant ethical guidelines for medical research in Japan. Informed consent was obtained from all participants implicitly when completing the baseline questionnaire, in which the purpose and methods of study were well described and explained. The STROBE checklist was used to check items that should be included in the article.

Of the 71698 women, those with non-Japanese nationality $(n=20)$, pre-commencement emigration $(n=86)$, incorrect birth data $(n=5)$, duplicate registration $(n=4)$ or late report of migration before the start of the follow-up period $(n=4626)$ were excluded. Of those remaining, 60002 women (89.6\%) returned the completed questionnaire. Of eligible subjects, 49279 (82.1\%) completed relevant questions including parity, age at first birth, experience of breastfeeding, age at menarche, age at menopause, exogenous hormone use, height, weight, smoking habits, alcohol consumption, perceived stress level, living with a spouse, and history of disease.

Follow-up and assessment of outcome. Participants were followed from the baseline survey $(1990,1994)$ until the date of death, last confirmed date of survival for participants who moved out of the study area (i.e., migration), or end of follow-up (December 31, 2014), whichever came first. The subjects from Katsushika and Suita public health center areas were scheduled to be followed for 20 years, until December 2009 and 2012, respectively. Survival or residential relocation of participants of the study areas was identified using public registries. During the study period, 8477 (14.1\%) died, $35(<0.06 \%)$ emigrated outside of Japan, and $469(0.8 \%)$ were lost to follow-up.

Death certificates were collected through the local public health centers and used to confirm the cause of death, with permission from the Ministry of Health, Labor and Welfare. Causes of death were defined according to the International Classification of Diseases, $10^{\text {th }}$ edition (ICD-10): all external causes (V01-Y89); intentional self-harm, namely suicide (X60-X84, Y87.0); and accidents (V01-X59, Y85-Y86). 
Exposure assessment. Reproductive events captured at the baseline survey were selected on the basis of prior research ${ }^{31}$, and categorized into tertiles or quartiles based on the frequency distribution within the cohort; the total number of live or still births (nulliparous versus parous, and $1,2,3$, or $\geq 4$ births), experience of breastfeeding (no or yes), age at first birth ( $\leq 23,24-26$, or $\geq 27$ years), age at menarche ( $\leq 13,14-15$, or $\geq 16$ years), exogenous hormone use (never or ever), menopausal status (pre-menopause, natural menopause, or surgical menopause) and age at menopause (pre-menopause, $\leq 47,48-50$, or $\geq 51$ years). We calculated total fertility years as the interval between menarche and menopause ( $\leq 32,33-36$, or $\geq 37$ years).

Statistical analysis. All analyses were performed with STATA version 14.0 (StataCorp LP). Cox proportional hazards regression models were employed to estimate the hazard ratios (HR) and 95\% confidence intervals (CI) to assess the risk of death by all external causes, suicide, and accidents according to reproductive factors using the STCOX command. Participants who were missing information on relevant reproductive factors or other covariates were excluded, leaving a total of 49279 women in the primary analyses.

Age was used as the time scale for all models. The minimum model (Model 1) was built with stratification by 11 study areas to allow a different baseline hazard due to the varying distribution of suicide rates across Japan ${ }^{32}$. The second model (Model 2) was adjusted for a priori covariates and several reproductive factors as follows: body mass index (BMI, in $\mathrm{kg} / \mathrm{m}^{2} ;<21.9,22$ to 24.9 , or $\left.\geq 25\right)^{33,34}$; smoking status (never or ever) ${ }^{35}$; alcohol consumption (no, occasional, or regular) ${ }^{36}$; perceived stress level (a little, average, or stressful) ${ }^{37}$; living with spouse (no or yes $)^{38,39}$; past history of disease ${ }^{35,40}$, including cancer, stroke, heart disease, diabetes mellitus, and hypertension (no, or yes); parity ${ }^{8}$; age at menarche ${ }^{14}$; menopausal status ${ }^{19}$; and exogenous hormone use ${ }^{13}$. Living with a spouse was used as a surrogate of marital status. Breastfeeding and age at first birth ${ }^{8}$ were included in the second model when analyses were restricted to parous women.

Effects of $p$-values for linear trends were assessed for parity, age at first birth, age at menarche, age at menopause and total fertility years by assigning ordinal variables. A likelihood ratio test was conducted to compare models with and without interaction terms and to calculate a $p$-value for statistical interaction between reproductive factors and confounders. Proportional hazards assumptions were verified using Schoenfeld residuals, and no variable violated the $\mathrm{PH}$ assumption (Supplementary Fig. S1).

Stratified analysis by menopausal status at baseline was conducted because menopausal transition or menopausal status is likely to be a high risk for suicide or accidents ${ }^{19,25-27}$. For sensitivity analysis, we used the multiple imputations approach with 20 iterations to impute missing values to assess the degree of selection bias due to complete case analysis (details available in the footnote of Supplementary Table S2). The Fine and Gray model was conducted to assess competing risk of death from all causes, except external causes, using the STCRREG command ${ }^{41}$. All $p$-values reported were two-sided, and $\mathrm{p}<0.05$ was set as the significance level.

\section{Results}

During 1028583 person-years (an average of 20.9 years) of follow-up for 49279 women, a total of 328 deaths by all external causes, 148 suicides (45\%), and 167 accidents (51\%) were identified. In the remaining $4 \%$ of all external causes of death, we observed $6(1.8 \%)$ deaths due to violence, $4(1.2 \%)$ deaths due to an undetermined cause, and $3(0.9 \%)$ deaths due to a medical procedure. The median age of death was 63 years old (IQR $=56-71)$ for suicide and 69 years old $(\mathrm{IQR}=61-75)$ for accidents. In comparison with the age of deaths from all causes $(73$ years old, IQR $=65-80)$, study subjects died 10 earlier years by suicide.

Among subjects, $53.7 \%$ of women reported pre-menopausal status at the baseline survey (Table 1). Several variables varied by menopausal status; pre-menopausal women were younger, and reported less breastfeeding, younger age at menarche and more exogenous hormones use than post-menopausal women. When we compared the subjects with and without missing data for all relevant variables, $17.9 \%$ of subjects had at least one missing datum (Supplementary Table S1).

Table 2 presents unadjusted and multivariable-adjusted HRs with 95\% CIs of mortality risk by all external causes according to female reproductive factors for all women, with estimations for stratified analyses by menopausal status. A decreased risk of all external causes was observed in parous women with ever breastfeeding [0.67 (95\% CI: 0.49-0.92)]. A marginally inverse association was found in women with three births compared to the reference group [ 2 births: reference; 1 birth: 1.07 (95\% CI: 0.71-1.62); 3 births: 0.75 (95\% CI: 0.55-1.01); $\geq 4$ births: 0.99 (95\% CI: 0.62-1.57): $\left.P_{\text {trend }}=0.74\right]$. A suggestive increased risk trend was found in women with later age at menarche [ $\leq 13$ years: reference; 14-15: 1.48 (95\% CI: 1.09-2.00); $\geq 16: 1.38$ (95\% CI: 0.97-1.96); $\left.P_{\text {trend }}=0.07\right]$. In stratified analysis, increased risk due to late age at menarche was more pronounced among pre-menopausal women. However, there was no statistically significant interaction among all reproductive factors.

A lowered risk of suicide was evident in ever versus never parity [0.53 (95\% CI: 0.32-0.88)] (Table 3). Parity with three births was inversely associated with risk of suicide compared to the reference group [2 births: reference; 1 birth: 1.12 (95\% CI: 0.61-2.04); 3 births: 0.61 (95\% CI: 0.39-0.97); $\geq 4$ births: 0.91 (95\% CI: 0.54-1.53); $\left.P_{\text {trend }}=0.24\right]$.

Parous women who ever breastfed versus never had a much lower risk of death by accidents [0.63 (95\% CI: 0.40 0.97)] (Table 4). Insignificant positive associations were observed among women with late age at menarche $[\leq 13$ years: reference; 14-15: 1.55 (95\% CI: 0.96-2.51); $\geq 16: 1.54$ (95\% CI: 0.92-2.60); $\left.P_{\text {trend }}=0.10\right]$ and ever use of exogenous hormones [1.45 (95\% CI: 0.93-2.25)]. The effect of age at menarche was more evident in pre-menopausal women, as was that for exogenous hormone use in post-menopausal women, although neither $p$-value for interaction was significant.

Compared with complete-case analyses, estimations derived from multiple imputations did not change substantially in terms of the magnitude or direction of the association between all reproductive factors and mortality risks of all external causes, suicide, and accidents (Supplementary Table S2). One exception was the association between accidents and breastfeeding. Regardless of increased sample size, this inverse association became null [0.75 (95\% CI: $0.50-1.14)]$. In the competing risk approach, the subhazard ratios for injury did not substantially differ. 


\begin{tabular}{|c|c|c|c|}
\hline \multirow[b]{2}{*}{ Characteristic } & \multirow[b]{2}{*}{ Total } & \multicolumn{2}{|c|}{ Menopausal status at inclusion } \\
\hline & & Pre-menopause & Post-menopause \\
\hline Number of subjects (n) & 49279 & $26456(53.7 \%)$ & $22824(46.3 \%)$ \\
\hline Age at recruitment, $\mathrm{y}^{\mathrm{a}}$ & $50.9(7.8)$ & $44.6(4.0)$ & $56.3(6.1)$ \\
\hline $\operatorname{BMI}\left(\mathrm{Kg} / \mathrm{m}^{2}\right)^{\mathrm{a}}$ & $23.3(3.2)$ & $23.1(3.1)$ & $23.6(3.3)$ \\
\hline Never smoker (\%) & 90.3 & 88.2 & 83.1 \\
\hline Non-drinker (\%) & 74.2 & 66.5 & 80.8 \\
\hline High perceived stress (\%) & 16.5 & 23.2 & 16.5 \\
\hline Living with spouse (\%) & 79.2 & 82.7 & 76.2 \\
\hline History of diseases (\%) & 19.2 & 3.9 & 27.7 \\
\hline \multicolumn{4}{|l|}{ Reproductive factors } \\
\hline Parity $^{\mathrm{a}}$ & $2.7(1.5)$ & $2.4(1.2)$ & $2.8(1.7)$ \\
\hline Age at first birth, $\mathrm{y}^{\mathrm{a}, \mathrm{b}}$ & $25.0(3.5)$ & $25.2(3.5)$ & $24.9(3.5)$ \\
\hline Ever breastfed (\%) ${ }^{\mathrm{b}}$ & 86.8 & 84.5 & 88.9 \\
\hline Age at menarche, $y^{a}$ & $14.5(1.9)$ & $13.7(1.5)$ & $15.1(1.9)$ \\
\hline Age at menopause, $\mathrm{y}^{\mathrm{a}, \mathrm{c}}$ & $48.1(4.8)$ & & $48.1(4.8)$ \\
\hline Total fertility years ${ }^{\mathrm{a}, c, \mathrm{~d}}$ & $33.0(4.8)$ & & $33.0(4.8)$ \\
\hline Ever use of exogenous hormones (\%) & 13.4 & 14.0 & 12.8 \\
\hline
\end{tabular}

Table 1. Basic characteristics of study subjects at baseline survey of the JPHC study. BMI, Body mass index; y, year. ${ }^{a}$ Mean (standard deviation). ${ }^{b}$ Parous women only. ${ }^{\mathrm{c}}$ Post menopause only. ${ }^{\mathrm{d}}$ Total fertility years as the interval between menarche and menopause.

\section{Discussion}

Based on a large-scale population-based cohort study with 1028583 person-years, our results support the vital roles of parity and breastfeeding in the risk of all-cause and major causes of external deaths. Age at menarche and exogenous hormone use were associated with death by all injuries or accidents. Age at menarche and exogenous hormone use were also potential makers for injury. Suicide and accidents accounted for $45 \%$ and $51 \%$ of external causes of death, respectively, and thus estimations of all external causes were similar to those for suicide or accidents. Our data also revealed null associations between mortality risk by external causes and several reproductive factors, including age at first birth, menopausal status, age at menopause, and years of fertility.

Parity. The decreased risk of suicide in women with ever parity regardless of marital status is consistent with previous studies $^{9,12}$. A negative influence of being single (never married, separated, divorced, or widowed) is commonly quoted as a risk factor for suicide, but its impact is not much stronger in women than men ${ }^{39,42}$. Parenthood has an essential role in protecting from suicide ${ }^{4}$, and this effect may be much stronger when children are young ${ }^{7}$. Motherhood itself may contribute to protecting against suicide in women by inculcating a feeling of responsibility and self-worth, enhancing the social network and providing a positive social role ${ }^{43}$. The presence of a child may play a significant role in the decision not to commit suicide, especially while the child is dependent ${ }^{8}$. Older women tend to count on their adult children more than their spouse for help in difficulties with daily life ${ }^{44}$. As the main reason for suicide among Japanese women is physical and mental illness ${ }^{45}$, an adult child may confer significant emotional and material support for parents in late life.

In this study, three births were associated with the lowest risk of suicide among parous women. In contrast, previous studies suggested an association between risk of suicide and increasing parity ${ }^{8}$, high parity ${ }^{11}$ or no clear pattern ${ }^{12}$. The lack of a linear trend in this study may be due to the adverse effect of a large family. This possibly imposes excessive burden from physical and mental stress and economic strain on parents ${ }^{14,46}$. A selection effect might also explain the association between parity and suicide ${ }^{15}$. Women who are single because they never married or were divorced or widowed might have been aggregated to the never/low parity group. A poor health status that prevents women from becoming pregnant or completing a pregnancy, or psychiatric illness, may influence the decision to marry and have more children ${ }^{47}$.

Breastfeeding. Ever breastfeeding was inversely associated with mortality risk from all external causes and accidents. In particular, a much lower risk of accidents was seen among postmenopausal women. Because no previous literature has investigated the association between breastfeeding and external causes of death, no explanation for these associations is available. One possible pathway is the protective effect of breastfeeding on several diseases after menopause including cancer, hypertension, diabetes, hyperlipidemia, and cardiovascular disease $\mathrm{e}^{48,49}$. These are likely to increase the risk of external cause of death ${ }^{35,40,50}$. Another possible explanation is the protective effect of breastfeeding on osteoporosis and subsequent fracture occurrence ${ }^{51,52}$, and Alzheimer disease $(\mathrm{AD})^{53}$, albeit that these associations remain inconclusive. However, because the association became insignificant after imputations regardless of increased sample size, this finding should be interpreted with care. The lack of detailed information on breastfeeding, such as frequency and duration, require further investigation to confirm this intriguing association between breastfeeding and the risk of death by accidents.

Menstruation and exogenous hormone use. The marginal positive associations we saw between late age at menarche and risk of all injuries and accidents may be explained by risk of cognitive impairment ${ }^{54-57}$ or 


\begin{tabular}{|c|c|c|c|c|c|c|c|c|c|c|c|c|c|c|}
\hline \multirow[b]{3}{*}{ Variable } & \multirow[b]{3}{*}{ Category } & \multirow{3}{*}{$\begin{array}{l}\text { Person- } \\
\text { years }\end{array}$} & \multicolumn{5}{|c|}{ All women } & \multicolumn{3}{|c|}{ Pre-menopause } & \multicolumn{3}{|c|}{ Post-menopause } & \multirow[b]{3}{*}{$P_{\text {int }}{ }^{\mathrm{c}}$} \\
\hline & & & \multirow[b]{2}{*}{ Cases } & \multicolumn{2}{|c|}{ Model $1^{\mathrm{a}}$} & \multicolumn{2}{|c|}{ Model $2^{b}$} & \multirow[b]{2}{*}{ Cases } & \multicolumn{2}{|c|}{$\operatorname{Model} 2^{b}$} & \multirow[b]{2}{*}{ Cases } & \multicolumn{2}{|c|}{$\operatorname{Model} 2^{b}$} & \\
\hline & & & & HR & $95 \% \mathrm{CI}$ & HR & $95 \% \mathrm{CI}$ & & HR & $95 \% \mathrm{CI}$ & & HR & $95 \% \mathrm{CI}$ & \\
\hline \multirow{2}{*}{ Parous } & No & 71289 & 31 & 1.00 & ref & $1.00^{\mathrm{h}}$ & ref & 13 & $1.00^{\mathrm{h}}$ & ref & 18 & $1.00^{\mathrm{h}}$ & ref & 0.18 \\
\hline & Yes & 957293 & 298 & 0.67 & $0.46-0.97$ & 0.77 & $0.52-1.15$ & 88 & 0.61 & $0.32-1.16$ & 209 & 0.90 & $0.54-1.48$ & \\
\hline \multirow{5}{*}{ Parity $^{d}$} & 1 & 77207 & 30 & 1.24 & $0.83-1.86$ & 1.07 & $0.71-1.62$ & 11 & 1.09 & $0.55-2.15$ & 19 & 1.04 & $0.62-1.74$ & 0.45 \\
\hline & 2 & 371068 & 117 & 1.00 & ref & 1.00 & ref & 45 & 1.00 & ref & 72 & 1.00 & ref & \\
\hline & 3 & 291703 & 71 & 0.74 & $0.55-0.99$ & 0.75 & $0.55-1.01$ & 17 & 0.53 & $0.55-2.15$ & 54 & 0.86 & $0.60-1.24$ & \\
\hline & $\geq 4$ & 217314 & 79 & 1.06 & $0.76-1.48$ & 0.99 & $0.62-1.57$ & 15 & 0.94 & $0.49-1.80$ & 64 & 1.12 & $0.75-1.65$ & \\
\hline & $P_{\text {trend }^{\mathrm{g}}}{ }^{\mathrm{g}}$ & & & 0.34 & & 0.74 & & & 0.86 & & & 0.58 & & \\
\hline \multirow{4}{*}{ Age at first birth, $y^{d}$} & $\leq 22$ & 213668 & 76 & 1.00 & ref & 1.00 & ref & 21 & 1.00 & ref & 55 & 1.00 & ref & 0.89 \\
\hline & $23-26$ & 485409 & 142 & 0.91 & $0.68-1.22$ & 0.95 & $0.71-1.27$ & 43 & 0.93 & $0.54-1.60$ & 99 & 0.97 & $0.69-1.37$ & \\
\hline & $\geq 27$ & 258786 & 79 & 1.03 & $0.74-1.43$ & 1.01 & $0.72-1.43$ & 24 & 1.07 & $0.57-1.99$ & 55 & 1.02 & $0.68-1.55$ & \\
\hline & $P_{\text {trend }^{\mathrm{g}}}^{\mathrm{g}}$ & & & 0.84 & & 0.94 & & & 0.82 & & & 0.91 & & \\
\hline \multirow{2}{*}{ Breastfeeding ${ }^{\mathrm{d}}$} & Never & 125722 & 51 & 1.00 & ref & 1.00 & ref & 22 & 1.00 & ref & 29 & 1.00 & ref & 0.59 \\
\hline & Ever & 831570 & 246 & 0.64 & $0.47-0.88$ & 0.67 & $0.49-0.92$ & 66 & 0.62 & $0.38-1.02$ & 180 & 0.71 & $0.47-1.08$ & \\
\hline \multirow{4}{*}{ Age at menarche, $y$} & $\leq 13$ & 316896 & 65 & 1.00 & ref & 1.00 & ref & 27 & 1.00 & ref & 38 & 1.00 & ref & 0.12 \\
\hline & $14-15$ & 466496 & 165 & 1.49 & $1.10-2.01$ & 1.48 & $1.09-2.00$ & 59 & 1.99 & $1.24-3.17$ & 106 & 1.15 & $0.78-1.69$ & \\
\hline & $\geq 16$ & 245189 & 98 & 1.43 & $1.01-2.02$ & 1.38 & $0.97-1.96$ & 15 & 2.35 & $1.21-4.55$ & 83 & 1.03 & $0.68-1.56$ & \\
\hline & $P_{\text {trend }^{\mathrm{g}}}^{\mathrm{g}}$ & & & 0.06 & & 0.07 & & & 0.01 & & & 0.88 & & \\
\hline \multirow{2}{*}{ Exogenous hormone use } & Never use & 887175 & 282 & 1.00 & ref & 1.00 & ref & 91 & 1.00 & ref & 191 & 1.00 & ref & 0.07 \\
\hline & Ever use & 141407 & 46 & 1.08 & $0.79-1.50$ & 1.07 & $0.78-1.48$ & 10 & 0.66 & $0.34-1.27$ & 36 & 1.31 & $0.90-1.90$ & \\
\hline \multirow{3}{*}{ Menopausal status } & Pre menopause & 481912 & 101 & 0.94 & $0.62-1.44$ & 1.00 & $0.72-1.37$ & & & & & & & \\
\hline & Natural menopause & 452624 & 193 & 1.00 & ref & 1.00 & ref & & & & & & & \\
\hline & Surgical menopause & 94046 & 34 & 1.05 & $0.60-1.86$ & 0.89 & $0.61-1.30$ & & & & & & & \\
\hline \multirow{4}{*}{ Age at menopause, $y^{\mathrm{e}}$} & $\leq 47$ & 177875 & 72 & 1.00 & ref & 1.00 & ref & & & & & & & \\
\hline & $48-50$ & 210330 & 86 & 0.95 & $0.69-1.31$ & 0.92 & $0.65-1.30$ & & & & & & & \\
\hline & $\geq 51$ & 158485 & 69 & 0.94 & $0.66-1.32$ & 0.92 & $0.63-1.33$ & & & & & & & \\
\hline & $P_{\text {trend }^{\mathrm{g}}}^{\mathrm{g}}$ & & & 0.71 & & 0.66 & & & & & & & & \\
\hline \multirow{4}{*}{ Total fertility span, $\mathrm{y}^{\mathrm{e}, \mathrm{f}}$} & $\leq 32$ & 204419 & 82 & 1.00 & ref & 1.00 & ref & & & & & & & \\
\hline & $33-35$ & 167339 & 70 & 0.97 & $0.70-1.34$ & 0.94 & $0.67-1.33$ & & & & & & & \\
\hline & $\geq 36$ & 174911 & 75 & 0.95 & $0.69-1.31$ & 0.92 & $0.64-1.33$ & & & & & & & \\
\hline & $P_{\text {trend }^{\mathrm{g}}}$ & & & 0.76 & & 0.67 & & & & & & & & \\
\hline
\end{tabular}

Table 2. Hazard ratios (HRs) and $95 \%$ confidence intervals (CIs) of death by all external causes according to reproductive factors for all women, pre-menopausal women, and post-menopausal women in the JPHC study. HR, Hazard ratio; CI, Confidence interval; y, year; BMI, Body mass index. ${ }^{a}$ Cox proportional hazards models (using attained age as time scale) stratified by 11 public health center areas. ${ }^{b}$ Based on model 1 and adjusted for BMI, smoking habit, alcohol consumption, perceived stress level, living with a spouse, history of disease, parity, age at menarche, menopausal status, and exogenous hormone use. ${ }^{\mathrm{P}} \mathrm{P}$ value for interaction of likelihood ratio test. ${ }^{\mathrm{d}}$ Parous women only with additional adjustment for age at first birth and breastfeeding. ${ }^{\mathrm{e}}$ Menopausal women only. ${ }^{\mathrm{f}}$ Total fertility years as the interval between menarche and menopause. ${ }^{g} P$ value for linear trend across categories of variable. ${ }^{\mathrm{h}}$ Adjustments as in footnote $\mathrm{b}$ except for parity.

osteoporosis ${ }^{5,57}$ in later life. The delayed initiation of secretion of gonadal sex steroid influences musculoskeletal function ${ }^{57,58}$. Estrogen plays a positive role in regulating neuronal biochemistry and cognitive function ${ }^{59}$. However, evidence from epidemiological studies on the association between early and/or long exposure to estrogen and cognitive function remains inconclusive $e^{54,55,60}$.

Positive associations between external cause of death and women with ever use of OCs has been reported ${ }^{13,17,18}$. In contrast, controversy remains with regard to hormone therapy use ${ }^{61,62}$. Nevertheless, despite a potential link between exogenous hormone use and risk of injuries, earlier studies did not provide potential biological mechanisms through which exogenous hormone use might modulate the risk of injuries. Although we also showed a marginally increased risk of accidents among ever users of exogenous hormones, a lack of data limited our ability to assess the effects of OCs and HT separately. Furthermore, differences in exogenous hormone availability and formulation may prevent comparison across studies.

Our study found null associations for age at menopause, fertility years and menopausal status with risk of suicide. As the perimenopause period carries a particular risk for developing depression and higher suicidal behaviors ${ }^{19}$, we expected a high risk of suicide among premenopausal women. In fact, suicide is the second cause of death among Japanese women aged 30-49 years old, and its rank decreases as age category rises ${ }^{63}$. Interactions between hormonal change and several stressful life events such as interpersonal problems and empty nest experience may lead women to be susceptible to mental illness and subsequent suicide behaviors ${ }^{24,64}$. 


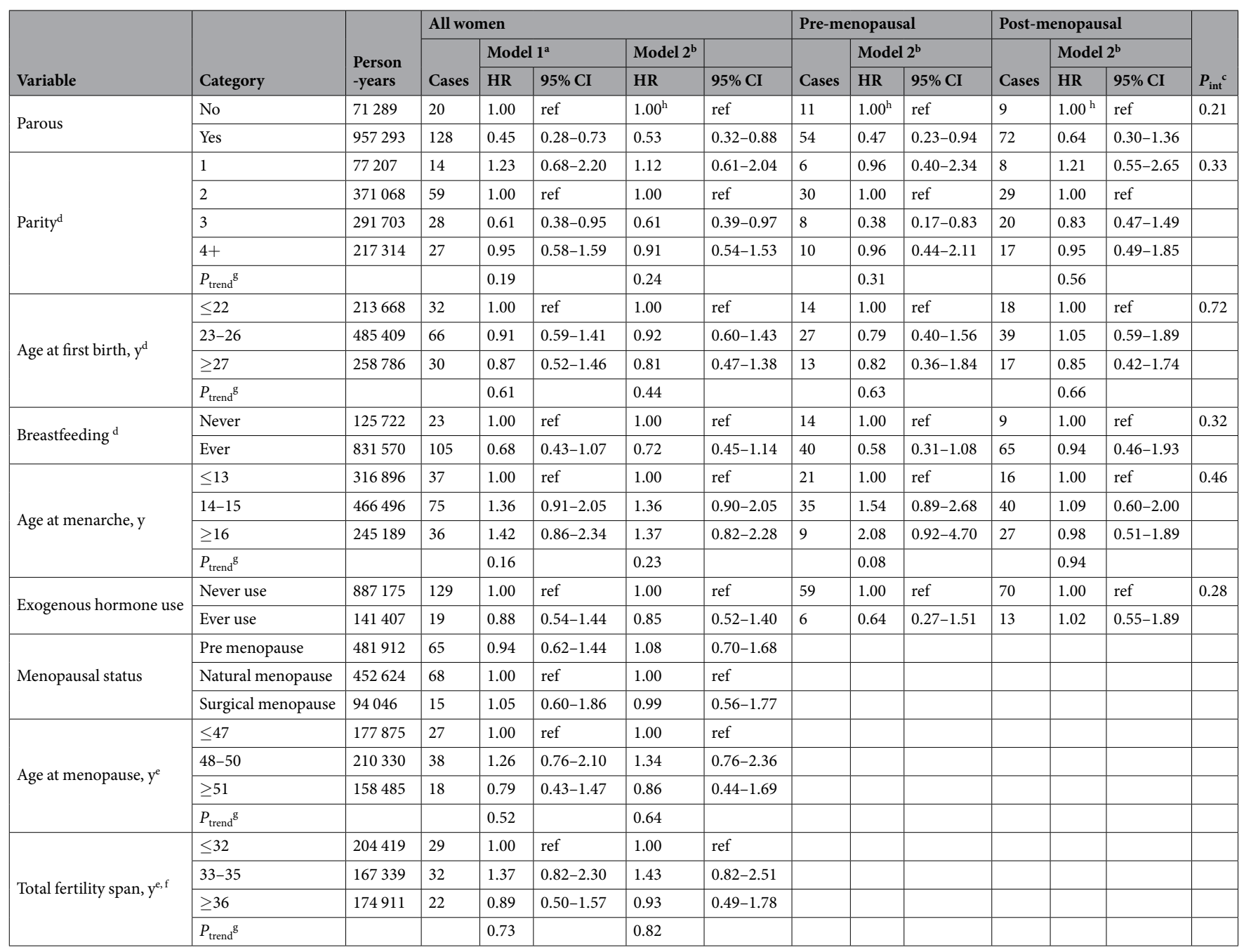

Table 3. Hazard ratios (HRs) and 95\% confidence intervals (CIs) of death by suicide according to reproductive factors for all women, pre-menopausal women, and post-menopausal women in the JPHC study. HR, Hazard ratio; CI, Confidence interval; y, year; BMI, Body mass index. ${ }^{a}$ Cox proportional hazards models (using

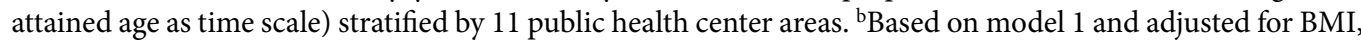
smoking habit, alcohol consumption, perceived stress level, living with a spouse, history of disease, parity, age at menarche, menopausal status and exogenous hormone use. ${ }^{c} \mathrm{P}$ value for interaction of likelihood ratio test. ${ }^{\mathrm{d}}$ Parous women only with additional adjustment for age at first birth and breastfeeding. ${ }^{\mathrm{e}}$ Menopausal women only. ${ }^{\text {fT}}$ Total fertility years as the interval between menarche and menopause. ${ }^{g} P$ value for linear trend across categories of variable. ${ }^{\mathrm{h}}$ Adjustment as in footnote b except for parity.

Importantly, suicide and accidents are never the consequence of a single cause; a combination of personal, cultural, social and biological features likely interact with fluctuations in sex hormones among women ${ }^{21,65,66}$. Although most of the reproductive factors are not modifiable, these factors are common exposures in women. A better understanding of how reproductive history influences long-term health may help to reduce avoidable deaths by self-harm and accidents.

Strengths and methodological issues. To our knowledge, this is the first large-scale prospective study to examine the impact of reproductive factors and the risk of external cause of death among Japanese. Strengths of the study include its large population-based sample with long follow-up period, prospective design, high response rate (more than $80 \%$ ) and low loss to follow-up. The availability of a variety of reproductive factors enabled a comprehensive assessment of the relationship between reproductive factors and external causes of death. Study participants consisted of a general population across Japan, making our findings generalizable to all middle-aged Japanese women. The potential of competing risks was not particularly high in our study. In addition, external cause of death usually occurs at younger ages than most other causes of death, and our study subjects were no exception.

Several limitations should also be mentioned. First, the main findings were obtained based on complete case analyses under the assumption of missing at random, which may have introduced selection bias. However, we addressed this issue by using the imputation approach. Second, single assessment only at the baseline survey may have resulted in misclassification. However, reproductive factors of post-menopausal women did not alter, 


\begin{tabular}{|c|c|c|c|c|c|c|c|c|c|c|c|c|c|c|}
\hline \multirow[b]{3}{*}{ Variable } & \multirow[b]{3}{*}{ Category } & \multirow{3}{*}{$\begin{array}{l}\text { Person- } \\
\text { years }\end{array}$} & \multicolumn{5}{|c|}{ All women } & \multicolumn{3}{|c|}{ Pre-menopausal } & \multicolumn{3}{|c|}{ Post-menopausal } & \multirow[b]{3}{*}{$P_{\text {int }}{ }^{\mathrm{c}}$} \\
\hline & & & \multirow[b]{2}{*}{ Cases } & \multicolumn{2}{|c|}{ Model $1^{\mathrm{a}}$} & \multicolumn{2}{|c|}{ Model $2^{b}$} & \multirow[b]{2}{*}{ Cases } & \multicolumn{2}{|c|}{ Model $2^{b}$} & \multirow[b]{2}{*}{ Cases } & \multicolumn{2}{|c|}{ Model $2^{b}$} & \\
\hline & & & & HR & $95 \% \mathrm{CI}$ & HR & 95\% CI & & HR & $95 \% \mathrm{CI}$ & & HR & $95 \% \mathrm{CI}$ & \\
\hline \multirow{2}{*}{ Parous } & No & 71289 & 10 & 1.00 & ref & $1.00^{\mathrm{h}}$ & ref & 1 & $1.00^{\mathrm{h}}$ & ref & 9 & $1.00^{\mathrm{h}}$ & ref & 0.54 \\
\hline & Yes & 957293 & 157 & 1.12 & $0.57-2.21$ & 1.23 & $0.62-2.44$ & 31 & 2.02 & $0.27-15.3$ & 113 & 1.11 & $0.54-2.30$ & \\
\hline \multirow{5}{*}{ Parity } & 1 & 77207 & 14 & 1.17 & $0.65-2.10$ & 1.10 & $0.61-1.99$ & 5 & 1.45 & $0.52-4.03$ & 9 & 0.95 & $0.46-1.96$ & 0.27 \\
\hline & 2 & 371068 & 56 & 1.00 & ref & 1.00 & ref & 16 & 1.00 & ref & 40 & 1.00 & ref & \\
\hline & 3 & 291703 & 40 & 0.84 & $0.56-1.27$ & 0.83 & $0.55-1.26$ & 9 & 0.76 & $0.33-1.75$ & 31 & 0.86 & $0.54-1.39$ & \\
\hline & $4+$ & 217314 & 47 & 1.15 & $0.73-1.80$ & 1.13 & $0.72-1.77$ & 4 & 0.69 & $0.21-2.24$ & 43 & 0.74 & $0.75-2.01$ & \\
\hline & $P_{\text {trend }^{\mathrm{g}}}$ & & & 0.99 & & 0.96 & & & 0.23 & & & 0.50 & & \\
\hline \multirow{4}{*}{ Age at first birth, $y^{d}$} & $\leq 22$ & 213668 & 40 & 1.00 & ref & 1.00 & ref & 6 & 1.00 & ref & 34 & 1.00 & ref & 0.54 \\
\hline & $23-26$ & 485409 & 73 & 0.87 & $0.58-1.31$ & 0.93 & $0.62-1.40$ & 17 & 1.18 & $0.45-3.12$ & 56 & 0.87 & $0.56-1.37$ & \\
\hline & $\geq 27$ & 258786 & 44 & 1.03 & $0.65-1.63$ & 1.05 & $0.65-1.71$ & 11 & 1.64 & $0.56-4.77$ & 33 & 0.93 & $0.54-1.61$ & \\
\hline & $P_{\text {trend }}^{\mathrm{g}}$ & & 44 & 0.91 & & 0.83 & & & 0.35 & & & 0.77 & & \\
\hline \multirow{2}{*}{ Breastfeeding $^{\mathrm{d}}$} & Never & 125722 & 26 & 1.00 & ref & 1.00 & ref & 8 & 1.00 & ref & 18 & 1.00 & ref & 0.23 \\
\hline & Ever & 831570 & 131 & 0.60 & $0.39-0.92$ & 0.63 & $0.40-0.97$ & 26 & 1.15 & $0.43-3.05$ & 105 & 0.52 & $0.31-0.89$ & \\
\hline \multirow{4}{*}{ Age at menarche, $y$} & $\leq 13$ & 316896 & 25 & 1.00 & ref & 1.00 & ref & 5 & 1.00 & ref & 20 & 1.00 & ref & 0.19 \\
\hline & $14-15$ & 466496 & 82 & 1.54 & $0.95-2.50$ & 1.55 & $0.96-2.51$ & 24 & 3.01 & $1.13-8.05$ & 58 & 1.17 & $0.67-2.02$ & \\
\hline & $\geq 16$ & 245189 & 60 & 1.59 & $0.95-2.66$ & 1.54 & $0.92-2.60$ & 6 & 3.36 & $0.99-11.4$ & 54 & 1.19 & $0.68-2.10$ & \\
\hline & $P_{\text {trend }}^{\mathrm{g}}$ & & & 0.12 & & 0.10 & & & 0.05 & & & 0.54 & & \\
\hline \multirow{2}{*}{$\begin{array}{l}\text { Exogenous hormone } \\
\text { use }\end{array}$} & Never use & 887175 & 140 & 1.00 & ref & 1.00 & ref & 31 & 1.00 & ref & 109 & 1.00 & ref & 0.24 \\
\hline & Ever use & 141407 & 27 & 1.44 & $0.93-2.23$ & 1.45 & $0.93-2.25$ & 4 & 0.72 & $0.25-2.08$ & 23 & 1.75 & $1.07-2.84$ & \\
\hline \multirow{3}{*}{ Menopausal status } & Pre menopause & 481912 & 25 & 0.96 & $0.58-1.59$ & 1.04 & $0.63-1.73$ & & & & & & & \\
\hline & Natural menopause & 452624 & 82 & 1.00 & ref & 1.00 & ref & & & & & & & \\
\hline & Surgical menopause & 94046 & 60 & 0.88 & $0.51-1.51$ & 0.85 & $0.49-1.47$ & & & & & & & \\
\hline \multirow{4}{*}{ Age at menopause, $\mathrm{y}^{\mathrm{e}}$} & $\leq 47$ & 177875 & 42 & 1.00 & ref & 1.00 & ref & & & & & & & \\
\hline & $48-50$ & 210330 & 45 & 0.78 & $0.50-1.22$ & 0.73 & $0.46-1.17$ & & & & & & & \\
\hline & $\geq 51$ & 158485 & 45 & 0.93 & $0.59-1.45$ & 0.87 & $0.54-1.40$ & & & & & & & \\
\hline & $P_{\text {trend }} \mathrm{g}$ & & & 0.77 & & 0.65 & & & & & & & & \\
\hline \multirow{4}{*}{$\begin{array}{l}\text { Total fertility span, } \\
y^{\mathrm{e}, \mathrm{f}}\end{array}$} & $\leq 32$ & 204419 & 51 & 1.00 & ref & 1.00 & ref & & & & & & & \\
\hline & $33-35$ & 167339 & 34 & 0.72 & $0.46-1.14$ & 0.70 & $0.43-1.13$ & & & & & & & \\
\hline & $\geq 36$ & 174911 & 47 & 0.90 & $0.59-1.36$ & 0.88 & $0.55-1.42$ & & & & & & & \\
\hline & $P_{\text {trend }}{ }^{\mathrm{g}}$ & 291703 & & 0.60 & & 0.62 & & & & & & & & \\
\hline
\end{tabular}

Table 4. Hazard ratios (HRs) and $95 \%$ confidence intervals (CIs) of death by accidents according to reproductive factors for all women, pre-menopausal women, and post-menopausal women in the JPHC study. HR, Hazard ratio; CI, Confidence interval; y, year; BMI, Body mass index. ${ }^{\mathrm{a} C o x}$ proportional hazards models (using attained age as time scale stratified by 11 public health center areas) based on model 1 and adjusted for BMI, smoking habit, alcohol consumption, perceived stress level, living with a spouse, history of disease, parity, age at menarche, menopausal status and exogenous hormone use. ${ }^{c} \mathrm{P}$ value for interaction of likelihood ratio test. ${ }^{\mathrm{d}}$ Parous women only with additional adjustment for age at first birth and breastfeeding. ${ }^{\mathrm{e}}$ Menopausal

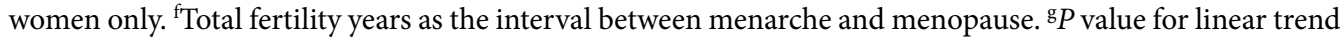
across categories of variable. ${ }^{\mathrm{h}}$ Adjustments as in footnote b except for parity.

apart from the experience of exogenous hormone use. Third, although we accounted for relevant covariates, we might have failed to obtain data for other possible confounders, such as psychiatric history, genetic and familial confounding, and socio-economic status. Fourth, specific details of breastfeeding (i.e., duration and frequency) and use of any exogenous hormone (i.e., formulation, dosage, and duration) were not available. Fifth, because distributions of reproductive factors varied across generations and cultural settings, our findings might not apply to women born at different times or in other populations around the world. Finally, injuries from huge disasters may have occurred regardless of potential risk factors. However we identified that no external cause of deaths occurred among study subjects in areas which experienced a major earthquake in 2011.

\section{Conclusions}

In summary, a lower risk of suicide was associated with ever parity and three births among parous women. Parous women who ever breastfed had a reduced risk of death by accidents. Given the few studies reported to date, our present results indicate the need for further studies to clarify the association between reproductive factors and the risk of external causes of death.

\section{Data Availability}

The datasets analyzed during the current study are not available due to no permission from the ethical board. 


\section{References}

1. World Health Organization. Injuries and violence: the facts 2014. (World Health Organization, Geneva, 2014).

2. Kodaka, M. et al. Exploring suicide risk factors among Japanese individuals: The largest case-control psychological autopsy study in Japan. Asian J Psychiatr 27, 123-126 (2017).

3. OECD. Health at a Glance 2017: OECD Indicators. (OECD publishing, Paris, 2017).

4. Durkheim E. Suicide: a study in sociology. (Free Press, New York, 1966).

5. Appleby, L. Suicide during pregnancy and in the first postnatal year. British medical journal 302, 137-140, https://doi.org/10.1136/ bmj.302.6769.137 (1991).

6. Marzuk, P. M. et al. Lower risk of suicide during pregnancy. Am J Psychiatry 154, 122-123, https://doi.org/10.1176/ajp.154.1.122 (1997).

7. Qin, P., Agerbo, E., Westergård-Nielsen, N., Eriksson, T. \& Mortensen, P. B. Gender differences in risk factors for suicide in Denmark. British Journal of Psychiatry 177, 546-550, https://doi.org/10.1192/bjp.177.6.546 (2000).

8. Yang, C. Y. Association between parity and risk of suicide among parous women. CMAJ: Canadian Medical Association journal = journal de l'Association medicale canadienne 182, 569-572, https://doi.org/10.1503/cmaj.090813 (2010).

9. Høyer, G. \& Lund, E. Suicide among women related to number of children in marriage. Arch Gen Psychiat 50, 134-137, https://doi. org/10.1001/archpsyc.1993.01820140060006 (1993).

10. Kvale, G., Heuch, I. \& Nilssen, S. Parity in relation to mortality and cancer incidence: a prospective study of Norwegian women. Int J Epidemiol 23, 691-699 (1994).

11. Hinkula, M., Kauppila, A., Näyhä, S. \& Pukkala, E. Cause-specific Mortality of Grand Multiparous Women in Finland. American Journal of Epidemiology 163, 367-373, https://doi.org/10.1093/aje/kwj048 (2006).

12. Green, A., Beral, V. \& Moser, K. Mortality in women in relation to their childbearing history. BMJ 297, 391-395 (1988).

13. Charlton, B. M. et al. Oral contraceptive use and mortality after 36 years of follow-up in the Nurses' Health Study: prospective cohort study. BMJ 349, g6356, https://doi.org/10.1136/bmj.g6356 (2014).

14. Koski-Rahikkala, H., Pouta, A., Pietilainen, K. \& Hartikainen, A. L. Does parity affect mortality among parous women? J Epidemiol Community Health 60, 968-973, https://doi.org/10.1136/jech.2005.044735 (2006).

15. Grundy, E. \& Kravdal, O. Fertility history and cause-specific mortality: a register-based analysis of complete cohorts of Norwegian women and men. Soc Sci Med 70, 1847-1857, https://doi.org/10.1016/j.socscimed.2010.02.004 (2010).

16. Mondul, A. M., Rodriguez, C., Jacobs, E. J. \& Calle, E. E. Age at natural menopause and cause-specific mortality. American Journal of Epidemiology 162, 1089-1097, https://doi.org/10.1093/aje/kwi324 (2005).

17. Hannaford, P. C. et al. Mortality among contraceptive pill users: cohort evidence from Royal College of General Practitioners' Oral Contraception Study. BMJ 340, c927, https://doi.org/10.1136/bmj.c927 (2010).

18. Colditz, G. Oral contraceptive use and mortality during 12 years of follow-up: the Nurses' Health Study. Annals of internal medicine 120, 821-826 (1994).

19. Usall, J. et al. Suicide ideation across reproductive life cycle of women Results from a European epidemiological study. Journal of affective disorders 116, 144-147, https://doi.org/10.1016/j.jad.2008.12.006 (2009).

20. Meltzer-Brody, S. New insights into perinatal depression: pathogenesis and treatment during pregnancy and postpartum. Dialogues in Clinical Neuroscience 13, 89-100 (2011).

21. Saunders, K. E. \& Hawton, K. Suicidal behaviour and the menstrual cycle. Psychological medicine 36, 901-912, https://doi. org/10.1017/s0033291706007392 (2006).

22. Baca-Garcia, E. et al. Suicide attempts among women during low estradiol/low progesterone states. Journal of psychiatric research 44 , 209-214 (2010).

23. Mann, J. J. Neurobiology of suicidal behaviour. Nat Rev Neurosci 4, 819-828, https://doi.org/10.1038/nrn1220nrn1220[pii] (2003).

24. Kodaka, M. et al. Female suicides: Psychosocial and psychiatric characteristics identified by a psychological autopsy study in Japan. Psychiatry Clin Neurosci 71, 271-279, https://doi.org/10.1111/pcn.12498 (2017).

25. Enns, D. L. \& Tiidus, P. M. The influence of estrogen on skeletal muscle: sex matters. Sports Med 40, 41-58, https://doi. org/10.2165/11319760-000000000-00000 (2010).

26. Muir, S. W., Gopaul, K. \& Montero Odasso, M. M. The role of cognitive impairment in fall risk among older adults: a systematic review and meta-analysis. Age and Ageing 41, 299-308, https://doi.org/10.1093/ageing/afs012 (2012).

27. Luine, V. N. Estradiol and cognitive function: Past, present and future. Hormones and behavior 66, 602-618, https://doi. org/10.1016/j.yhbeh.2014.08.011 (2014).

28. Yamamoto, S. \& Watanabe, S. Geographic characteristics and mortality profiles in the JPHC study. Japan Public Health Center-based Prospective Study on Cancer and Cardiovascular Diseases. Journal of epidemiology/Japan Epidemiological Association 11 (2001).

29. Tsugane, S. \& Sawada, N. The JPHC study: design and some findings on the typical Japanese diet. Jpn J Clin Oncol 44, 777-782, https://doi.org/10.1093/jjco/hyu096 (2014).

30. Watanabe, S., Tsugane, S., Sobue, T., Konishi, M. \& Baba, S. Study design and organization of the JPHC study. Japan Public Health Centerbased Prospective Study on Cancer and Cardiovascular Diseases. Journal of epidemiology/Japan Epidemiological Association 11 (2001).

31. Otsuki, S. et al. Female reproductive factors and risk of all-cause and cause-specific mortality among women: The Japan Public Health Center-based Prospective Study (JPHC study). Ann Epidemiol 28, 597-604 e596, https://doi.org/10.1016/j. annepidem.2018.06.001 (2018).

32. Suzuki, E., Kashima, S., Kawachi, I. \& Subramanian, S. V. Social and geographical inequalities in suicide in Japan from 1975 through 2005: a census-based longitudinal analysis. PLOS ONE 8 (2013).

33. Amiri, S. \& Behnezhad, S. Body mass index and risk of suicide: A systematic review and meta-analysis. Journal of affective disorders 238, 615-625, https://doi.org/10.1016/j.jad.2018.05.028 (2018).

34. Bhaskaran, K., Dos-Santos-Silva, I., Leon, D. A., Douglas, I. J. \& Smeeth, L. Association of BMI with overall and cause-specific mortality: a population-based cohort study of 3.6 million adults in the UK. Lancet Diabetes Endocrinol 6, 944-953, https://doi. org/10.1016/S2213-8587(18)30288-2 (2018).

35. Yamauchi, T. et al. History of diabetes and risk of suicide and accidental death in Japan: The Japan Public Health Centre-based Prospective Study, 1990-2012. Diabetes Metab 42, 184-191 (2016).

36. Dawson, D. A. Alcohol and mortality from external causes. J Stud Alcohol 62, 790-797 (2001).

37. Feskanich, D. et al. Stress and suicide in the Nurses' Health Study. J Epidemiol Community Health 56, 95-98, https://doi.org/10.1136/ jech.56.2.95 (2002).

38. Ikeda, A. et al. Marital status and mortality among Japanese men and women: the Japan Collaborative Cohort Study. BMC Public Health 7, 73, https://doi.org/10.1186/1471-2458-7-73 (2007).

39. Poudel-Tandukar, K. et al. Differences in suicide risk according to living arrangements in Japanese men and women-the Japan Public Health Center-based (JPHC) prospective study. Journal of affective disorders 131, 113-119 (2011).

40. Yamauchi, T. et al. Death by Suicide and Other Externally Caused Injuries After Stroke in Japan (1990-2010): The Japan Public Health Center-Based Prospective Study. Psychosom Med 76, 452-459, https://doi.org/10.1097/Psy.0000000000000079 (2014).

41. Fine, J. P. \& Gray, R. J. A Proportional Hazards Model for the Subdistribution of a Competing Risk. J Am Stat Assoc 94, 496-509, https://doi.org/10.1080/01621459.1999.10474144 (1999).

42. Cabinet office, G. o. J. White paper on suicide prevention in: digest version. 2015. (Cabinet office, Government of Japan, Tokyo, 2015).

43. Emiliy Grundy, N. S. Contact Between Adult Children and Their Parentes in Great Britain 1986-99. Encironment and Planning A: Economy and Space 33, 685-697 (2001). 
44. Nishioka, H. Parent-adult child relationship in Japan. (2000).

45. Yamamura, T., Kinoshita, H., Nishiguchi, M. \& Hishida, S. A perspective in epidemiology of suicide in Japan. Vojnosanit Pregl 63, 575-583 (2006).

46. Lund, E., Arnesen, E. \& Borgan, J. K. Pattern of childbearing and mortality in married women-a national prospective study from Norway. J Epidemiol Community Health 44, 237-240 (1990).

47. Qin, P. \& Mortensen, P. B. The impact of parental status on the risk of completed suicide. Arch Gen Psychiatry 60, 797-802, https:// doi.org/10.1001/archpsyc.60.8.797 (2003).

48. Schwarz, E. B. et al. Duration of lactation and risk factors for maternal cardiovascular disease. Obstet Gynecol 113, 974-982, https:// doi.org/10.1097/01.AOG.0000346884.67796.ca (2009).

49. Lord, S. J. et al. Breast cancer risk and hormone receptor status in older women by parity, age of first birth, and breastfeeding: a casecontrol study. Cancer epidemiology, biomarkers \& prevention: a publication of the American Association for Cancer Research, cosponsored by the American Society of Preventive Oncology 17, 1723-1730, https://doi.org/10.1158/1055-9965.EPI-07-2824 (2008).

50. Shen, Q. et al. Injuries before and after diagnosis of cancer: nationwide register based study. BMJ 354, https://doi.org/10.1136/bmj. i4218 (2016)

51. Salari, P. \& Abdollahi, M. The Influence of Pregnancy and Lactation on Maternal Bone Health: A Systematic Review. Journal of Family \& Reproductive Health 8, 135-148 (2014)

52. Crandall, C. J. et al. Associations of Parity, Breastfeeding, and Fractures in the Women's Health Observational Study. Obstet Gynecol 130, 171-180 (2017).

53. Fox, M., Berzuini, C. \& Knapp, L. A. Maternal breastfeeding history and Alzheimer's disease risk. J Alzheimers Dis 37, 809-821, https://doi.org/10.3233/jad-130152 (2013).

54. Ryan, J., Carriere, I., Scali, J., Ritchie, K. \& Ancelin, M. L. Life-time estrogen exposure and cognitive functioning in later life. Psychoneuroendocrinology 34, 287-298, https://doi.org/10.1016/j.psyneuen.2008.09.008 (2009).

55. Karim, R. et al. Effect of Reproductive History and Exogenous Hormone Use on Cognitive Function in Mid- and Late Life. Journal of the American Geriatrics Society 64, 2448-2456, https://doi.org/10.1111/jgs.14658 (2016).

56. Jacobsen, B. K., Nilssen, S., Heuch, I. \& Kvale, G. Reproductive factors and fatal hip fractures. A Norwegian prospective study of 63,000 women. J Epidemiol Community Health 52, 645-650 (1998).

57. Shimizu, Y. et al. Menstrual and reproductive factors and risk of vertebral fractures in Japanese women: the Japan Public Health Center-based prospective (JPHC) study. Osteoporosis International, https://doi.org/10.1007/s00198-018-4665-8 (2018).

58. Clarke, B. L. \& Khosla, S. Female reproductive system and bone. Arch Biochem Biophys 503, 118-128, https://doi.org/10.1016/j. abb.2010.07.006 (2010).

59. Brinton, R. D. Estrogen-induced plasticity from cells to circuits: predictions for cognitive function. Trends in pharmacological sciences 30, 212-222, https://doi.org/10.1016/j.tips.2008.12.006 (2009).

60. Geerlings, M. I. et al. Reproductive period and risk of dementia in postmenopausal women. JAMA 285, 1475-1481 (2001).

61. HUNT, K., VESSEY, M. \& McPHERSON, K. Mortality in a cohort of long-term users of hormone replacement therapy: an updated analysis. BJOG: An International Journal of Obstetrics \& Gynaecology 97, 1080-1086, https://doi.org/10.1111/j.1471-0528.1990. tb02494.x (1990).

62. Petitti, D. B., Perlman, J. A. \& Sidney, S. Noncontraceptive estrogens and mortality: long-term follow-up of women in the Walnut Creek Study. Obstet Gynecol 70, 289-293 (1987).

63. Ministry of Health, L. A. W. J. In Yearly (Ministry of Health, Labour and Walfare Japan, 2018)

64. Pimenta, F., Leal, I., Maroco, J. \& Ramos, C. Menopausal symptoms: Do life events predict severity of symptoms in peri- and postmenopause? Maturitas 72, 324-331, https://doi.org/10.1016/j.maturitas.2012.04.006 (2012).

65. Yoshimasu, K., Kiyohara, C. \& Miyashita, K. \& The Stress Research Group of the Japanese Society for, H. Suicidal risk factors and completed suicide: meta-analyses based on psychological autopsy studies. Environmental Health and Preventive Medicine 13, 243-256, https://doi.org/10.1007/s12199-008-0037-x (2008).

66. Fassberg, M. M. et al. A systematic review of social factors and suicidal behavior in older adulthood. Int J Environ Res Public Health 9, 722-745, https://doi.org/10.3390/ijerph9030722ijerph9030722[pii] (2012).

\section{Acknowledgements}

We would like to thank all members of the JPHC Study group (JPHC Study Group members are listed at the following: http://epi.ncc.go.jp/en/jphc/781/3838.html.) for their contribution. This work was funded by the National Cancer Center Research and Development Fund (since 2010); a Grant-in-Aid for Cancer Research from the Ministry of Health, Labor and Welfare of Japan; and AMED-WISE, the Project for Whole Implementation to Support and Ensure the Female Life, Japan Agency for Medical Research and Development, AMED.

\section{Author Contributions}

M.I. and S.Ta. designed this project; S.Ts., N.S. and M.I. contributed to the study design and survey; S.Ta. conducted the statistical analysis and interpreted the results; S.Ta. wrote the manuscript; all authors reviewed, contributed to discussion and approved the final version of the manuscript.

\section{Additional Information}

Supplementary information accompanies this paper at https://doi.org/10.1038/s41598-019-50890-x.

Competing Interests: The authors declare no competing interests.

Publisher's note Springer Nature remains neutral with regard to jurisdictional claims in published maps and institutional affiliations.

Open Access This article is licensed under a Creative Commons Attribution 4.0 International License, which permits use, sharing, adaptation, distribution and reproduction in any medium or
format, as long as you give appropriate credit to the original author(s) and the source, provide a link to the Creative Commons license, and indicate if changes were made. The images or other third party material in this article are included in the article's Creative Commons license, unless indicated otherwise in a credit line to the material. If material is not included in the article's Creative Commons license and your intended use is not permitted by statutory regulation or exceeds the permitted use, you will need to obtain permission directly from the copyright holder. To view a copy of this license, visit http://creativecommons.org/licenses/by/4.0/.

(C) The Author(s) 2019 